\title{
Effect of Sugar, Urea, and Molasses and the Influence of Radiation on the Plasticization of Acacia catechu Extract Incorporated Starch/Poly-(Vinyl Alcohol) Based Film
}

\author{
Marufa Naznin ${ }^{1,2}$ and Md. Zainul Abedin ${ }^{1}$ \\ ${ }^{1}$ Department of Environmental Science, Independent University Bangladesh, Bashundhara, Dhaka, Bangladesh \\ ${ }^{2}$ BRAC International Program, BRAC, Dhaka, Bangladesh
}

Correspondence should be addressed to Md. Zainul Abedin; zainul_abedin.iub73@yahoo.com

Received 8 April 2013; Accepted 13 May 2013

Academic Editors: Y. Chen, S. Fakirov, and J. I. Velasco

Copyright (c) 2013 M. Naznin and Md. Z. Abedin. This is an open access article distributed under the Creative Commons Attribution License, which permits unrestricted use, distribution, and reproduction in any medium, provided the original work is properly cited.

\begin{abstract}
Acacia catechu extract was incorporated in the starch/PVA (60\%: $40 \%)$ based films $(0 \%$ to $15 \%)$ to the total weight of starch/PVA based film. The tensile strength (TS) of the starch/PVA blend film was $24 \mathrm{MPa}$ whereas the acacia incorporated film shows the highest tensile strength (TS) of $33.8 \mathrm{MPa}$ at $0.5 \%$. Again, $0.5 \%$ acacia based film was treated with $10 \%$ urea, sugar, and molasses separately both at nonirradiated and irradiated conditions. At the nonirradiated condition molasses incorporated film gives the best results (TS $16 \mathrm{MPa}$, EB 59\%), while sugar incorporated film shows a value of $10 \mathrm{MPa}$ TS and EB of $123 \%$ at $200 \mathrm{krad}$. The films were investigated by FTIR. Thermal studies were carried out by TG/DTA. Water absorption experiment showed a different uptake of water by the different films. Soil degradation test revealed that after 70 days molasses incorporated film (both irradiated and nonirradiated) degrades to $100 \%$ into the soil.
\end{abstract}

\section{Introduction}

Polysaccharides such as starch and dextrin are typical examples of natural biodegradable hydrophilic polymers with relatively good biocompatibility [1]. It has been known since the 1970s that starch is renewable and biodegradable [2]. Starch has been incorporated into synthesized polymer matrix, and in the past decades several efforts have been made to convert starch into a thermoplastic material [3-9].

As polysaccharides dissolve easily in water, they do not present mechanical and shape stabilities in fluids. An effective method for overcoming this issue is to blend them with synthesized polymer gel networks in order to form natural and synthesized polymer blend. Among the existing synthesized polymers, PVA possesses many useful properties, such as excellent chemical resistance, optical and physical properties [10], good film-forming capability, water solubility [11], and an excellent biocompatibility $[12,13]$. PVA is the most readily biodegradable material of vinyl polymers. It is readily degraded in wastewater-activated sludge. The microbial degradation of PVA has been studied [14-16].
The strength, flexibility, and water resistance of starch productions improved when PVA aqueous solution was added [17]. Furthermore, the polarity of PVA has been found to help the blend in accelerating the hydrolytic attack by the atmospheric moisture, thus resulting in the degradation of the sugar molecules in natural polymers [18]. Some effective means commonly used to modify the PVA/starch composites in order to improve their mechanical and water resistance properties include (a) chemically modifying PVA or starch [19], for example, esterification, oxidation, etherification, cross-linking, and methylation [20-26], (b) physically modifying the SP composites, for example, by adding corn fibers to the blends [18], or (c) chemically modifying the SP composites during or after the blending process, for example, crosslinking reactions, grafting [27], and surface modifications [28]. Examples of cross-linking reagents include glutaraldehyde [29], boric acid [30], and epichlorohydrin [31], and those methods include radiation [32] and photocross-linking [33]. However, cross-linking agents such as those mentioned above always display toxicity, and thus their potential applications as biomaterials are limited. 
Catechu (or Khair), a hot water extract of red heartwood of Acacia catechu, is a brown colored material, and the primary constituents are catechin, catechutannic acid, quercetin, and so forth [34]. Catechin and quercetin are polyphenolic compounds which are also proved to increase the mechanical properties of the polymeric films [35]. It has no problem of toxicity, and the ultimate goal is the production of environment friendly polymer.

Starch and PVA can be successfully used to form edible or biodegradable films [36]. When the film contains higher amount of starch than PVA in the blend, it becomes markedly brittle at low moisture content [37-40]. The addition of a plasticizer agent to the film is required to overcome film brittleness, caused by high intermolecular forces. In recent years extensive researches have been performed on the plasticization of starch/PVA blends using glycerol, sorbitol, urea, citric acid36, and complex plasticizers. However, few works have been performed on sugar and molasses (a viscous byproduct of sugar) as plasticizers.

Radiation technology has been used frequently to improve the properties of plastic products due to the chemical reaction among polymer molecules under irradiation [41, 42]. Due to the chemical reaction between PVA and starch molecules in PVA/starch blend systems induced by irradiation, the tensile strength of PVA hydrogels was improved obviously [43]. In this study, the effect of urea, sugar, and molasses at a fixed composition has been evaluated on the starch/PVA based film modified by Acacia catechu extract.

\section{Materials and Methods}

Polyvinyl alcohol (PVA) (MW 145000) and urea were purchased from Merck Schuchardt OHG, Hohenbrunn, Germany. Rice starch was collected from rice cooking waste of the kitchen. Acacia catechu extract, sugar, and molasses were purchased from local market.

2.1. Preparation of the Film. Films were prepared by the casting method. Starch and PVA were blended in hot water in a ratio of $60 \%: 40 \%$ at about $150^{\circ} \mathrm{C}$ for about 2 hours to form a homogeneous solution and acacia were incorporated in starch/PVA blends at $0 \%, 0.5 \%, 1 \%, 5 \%, 10 \%$, and $15 \%$ to the total weight of starch/PVA film. The solutions were then poured on the silicon paper covered glass plate. The solutions were maintained in a thickness of $4 \mathrm{~mm}$ on the glass plate. Water was evaporated from the moulds in an oven at $50^{\circ} \mathrm{C}$ for 10 hours. After cooling the dried films at room temperature for 72 hours, they were peeled from the silicon cloth and cut into small pieces of length $70 \mathrm{~mm}$ and width $10 \mathrm{~mm}$. The average thickness of the dried films was about $0.3 \mathrm{~mm}$. The film having the best mechanical property was chosen for further investigation. Urea, sugar, and molasses were incorporated in the optimized St/PVA/Ac (starch/PVA/Acacia) based film individually at 10 percent to the total weight of St/PVA/Ac based film. The films were stored in desiccators at room temperature $\left(30^{\circ} \mathrm{C}\right)$ and at $\mathrm{RH} 65 \%$ prior to performing the measurements.

2.2. Gamma Irradiation of the Film. After making films from different formulations, the film having the best mechanical property was chosen for irradiation by gamma rays $\left(60^{\circ} \mathrm{C}\right.$ gamma source, Inter Professional Investment Ltd, UK). The film was irradiated with $350 \mathrm{krad} / \mathrm{hr}$ dose rates at $200 \mathrm{krad}$ dose and after 24 hours, mechanical, thermal, and water absorption properties and soil burial test of the films were studied.

\subsection{Property Measurement}

2.3.1. Tensile Properties. Tensile strength (TS) and elongation at break (EB) of the films (both irradiated and nonirradiated) are measured with universal testing machine (HounsField, model H50ks-0404, RHi-50z, England). The load capacity was $500 \mathrm{~N}$. All the test samples were conditioned at $20^{\circ} \mathrm{C}$ and $50 \%$ relative humidity.

2.3.2. Fourier Transformed Infrared Spectroscopy (FTIR). The IR spectra of the films were measured by FTIR Spectrophotometer (PerkinElmer, UK). The FTIR spectrum was taken in transmittance mode. The spectra were obtained at a resolution of $8 \mathrm{~cm}^{-1}$ in the range of 650 to $4000 \mathrm{~cm}^{-1}$.

2.3.3. Thermal Analysis. The thermal test of the films was performed using computer controlled TG/DTA 6300 system controlled to an EXSTAR 6000 STATION, Seiko Instrument Inc., Japan. The TG/DTA module used a horizontal system balance mechanism. All the experiments were performed under the nitrogen atmosphere. Sample weights were 8$10 \mathrm{mg}$ and heating rate was $10^{\circ} \mathrm{C} / \mathrm{min}$ within the temperature range of $50-600^{\circ} \mathrm{C}$.

2.3.4. Water Absorption. The water absorption of the irradiated and nonirradiated films was monitored (up to 120 minutes) to find the profile of water uptake. Water absorption was determined using the following equation: $W_{g}=\left(W_{a}-\right.$ $\left.W_{o}\right) / W_{o} \times 100$, where $W_{a}$ and $W_{o}$ were the weights of the sample after and before soaking in water.

2.3.5. Soil Burial Test. The degradation tendency of the films (both irradiated and non-irradiated) in the soil was studied. The films were buried in soil for 1 to 10 weeks. Moisture content of the soil was maintained at around $15 \%-18 \%$. Every week, samples were taken out from the soil. After cleaning carefully and drying at room temperature, their weight losses were measured $[36,44]$. Weight losses $(\%)$ were determined using the following equation: $W_{g}=\left(W_{a}-W_{o}\right) / W_{a} \times 100$, where $W_{a}$ and $W_{o}$ were the weights of the sample before and after soil burial treatment.

\section{Results and Discussion}

3.1. Effects of Acacia catechu (Ac) Extracts on the Mechanical Properties of Starch/PVA (St/PVA) Film. Polymer materials such as films are subjected to various kinds of stress during their application; as a consequence the study of the mechanical properties is of primary importance for determining the performance of the materials [45]. The tensile strength (TS) and elongation at break (EB) of blend films are plotted as a function of the Acacia catechu content as shown in 


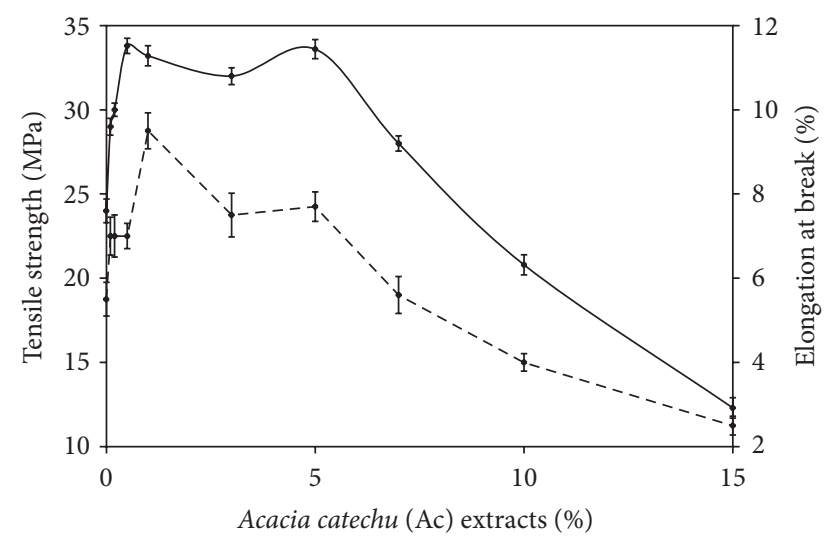

$\rightarrow$ TS

- EB

Figure 1: Effect of Acacia catechu (Ac) extracts on the tensile strength and elongation at break of St/PVA film. Data are expressed as mean \pm SEM.

Figure 1. It has been observed that the TS of the film increases initially with the increase of Ac extracts and after reaching a maximum value the TS and EB values begin to decrease. The TS of St/PVA (without Ac extracts) based film is $24 \pm$ $0.70 \mathrm{MPa}$ whereas the TS value become highest $(33.8 \pm$ $0.45 \mathrm{MPa}$ ) at $0.5 \% \mathrm{Ac}$ extracts incorporated film. In case of $\mathrm{EB}$, incorporation of Ac extracts in the St/PVA based film does not cause any remarkable change. Since $0.5 \%$ Ac extracts incorporated film exhibits the highest TS $(33.8 \pm 0.45 \mathrm{MPa})$, this film was considered for further investigation.

The improvement in mechanical properties of the films incorporated with Ac extracts may be attributed to the interaction between St/PVA and polyphenolic compounds from Ac extracts. There is a possibility that polyphenolic compounds may be able to fit into St/PVA based polymeric matrix and established interactions such as hydrogen bonding with $\mathrm{OH}$ groups of St/PVA [46]. Changes in mechanical properties as affected by polyphenolic compounds were also observed for other biopolymeric films [47-49]. However, after a certain value, with the increase of Ac extracts into the $\mathrm{St} / \mathrm{PVA}$ based film, the TS of the film gradually decreases. This sharp decrease of TS at higher concentration of Ac may be due to the lessening of compactness of the film components. As the percentage of catechuic acid and tannic acid increased in the St/PVA based film, this can cause a breakdown in the structure of St/PVA based film.

3.2. Effect of TS and EB of Urea, Sugar, and Molasses Incorporated St/PVA/Ac (Starch/PVA/Acacia) Based Film. Figures 2 and 3 represent the effect of TS and EB of $10 \%$ urea, $10 \%$ sugar, and $10 \%$ molasses on the St/PVA/Ac based film. The TS and EB of the St/PVA/Ac bases film are $33.8 \pm 0.45 \mathrm{MPa}$, and $9.5 \pm$ $0.43 \%$, respectively. From Figures 2 and 3 , it has been found that the incorporation of $10 \%$ urea decreases the TS tremendously $(5 \pm 0.26 \mathrm{MPa})$, but the percentage of $\mathrm{EB}$ is highly increased to $126.5 \pm 0.9 \%$, but in comparison, incorporation of sugar could not affect any lowering of TS $(16 \pm 0.5 \mathrm{MPa})$ significantly. However, the incorporation of sugar does not

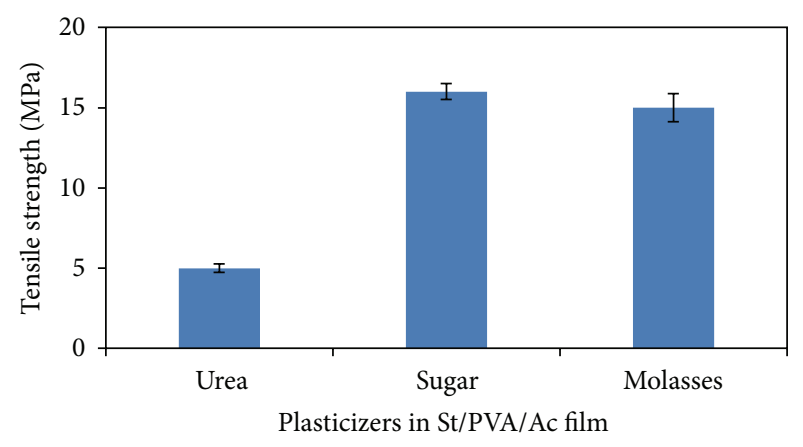

FIGURE 2: Effect of urea, sugar, and molasses on the TS of St/PVA/Ac blend film.

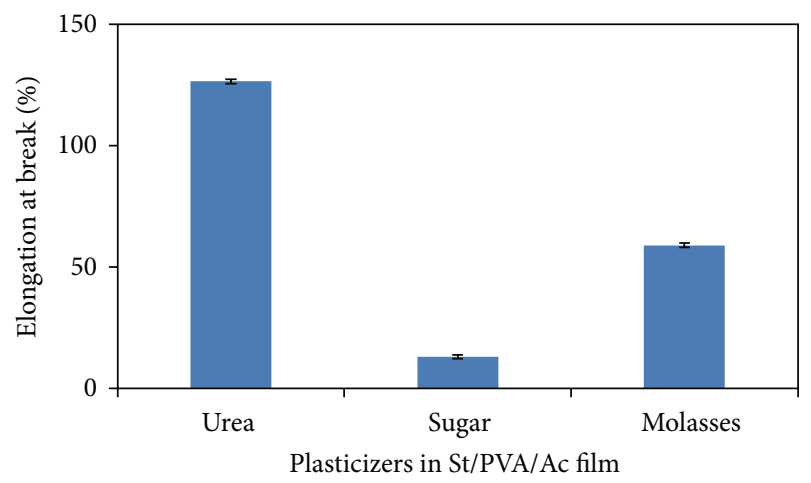

FIgURE 3: Effect of urea, sugar, and molasses on the EB of St/PVA/Ac blend film. Data are expressed as mean \pm SEM.

make any noticeable changes in the EB. And the molasses incorporated film shows moderate TS and $\mathrm{EB}(15 \pm 0.89 \mathrm{MPa}$ and $59 \pm 0.9 \%)$. This behavior can be explained taking into consideration the fact that the increase of urea amount in the blend results in a greater mobility of both the starch and the PVA macromolecules which enhance the flexibility of the resulting film [50]. In another work, it has been observed that the TS increased initially with the increase of sugar content [51]. In this study it has been observed that $10 \%$ sugar incorporation into the film (where the ratio of St:PVA is $60: 40)$ shows acceptable TS of $16 \pm 0.5 \mathrm{MPa}$ and low EB of $13 \pm 0.7 \%$. When lower percent of starch is added to the film, high EB was observed, and this was confirmed by other authors' also [36]. Nevertheless, maximum percent of starch content shows poor EB which was also proved by this study. Flexibility of a polymer is an essential parameter that is very actively considered during the application of the polymer. Flexibility and elasticity are two related phenomena that are associated with the stability of the application of polymer in a certain area [52]. The incorporation of $10 \%$ molasses exhibits the optimum performance for both TS and EB. The plasticizing effect of molasses increases the flexibility of the St/PVA/Ac/molasses blend film.

3.3. FTIR Analysis of Urea, Sugar, and Molasses Incorporated St/PVA/Ac Based Film. Figure 4 shows the comparison of FTIR spectra of St/PVA/Ac/urea, St/PVA/Ac/sugar, and 


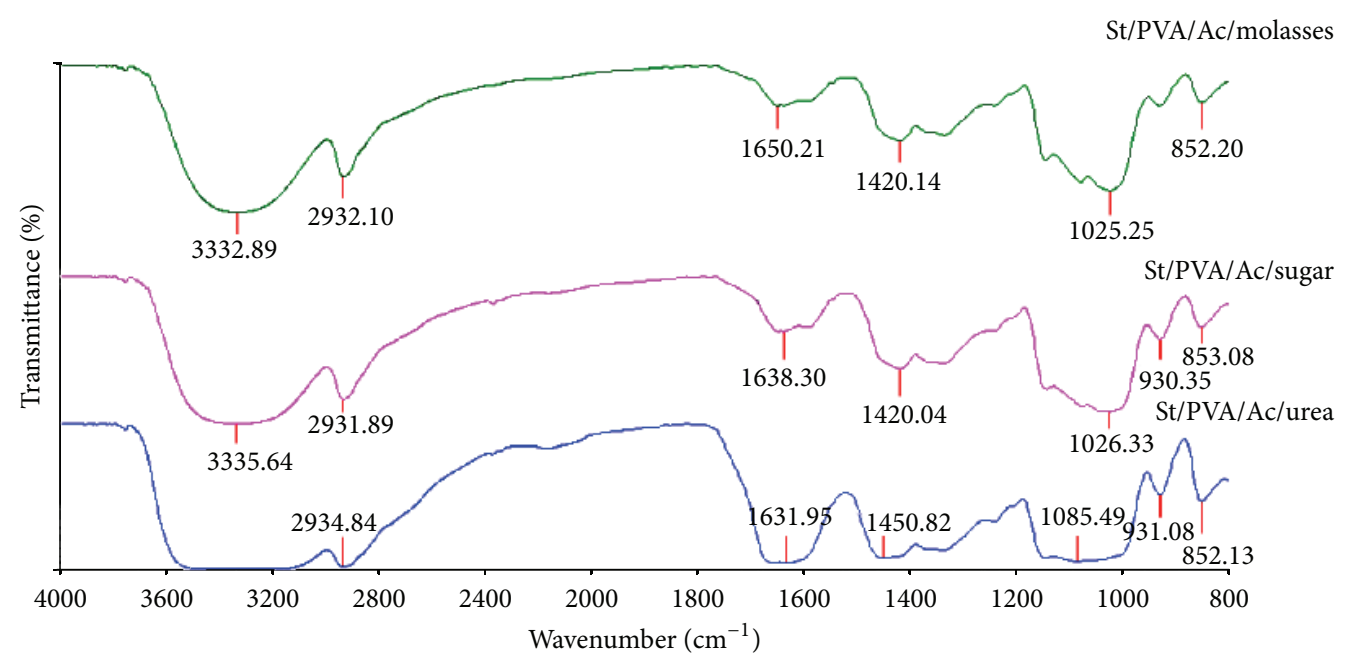

FiguRE 4: FTIR spectra of St/PVA/Ac/urea, St/PVA/Ac/sugar, and St/PVA/Ac/molasses films.

St/PVA/Ac/molasses films. FTIR spectra of these films are studied and FTIR analysis was used to characterize the effect of urea, sugar, and molasses incorporation on the St/PVA/Ac based blend film. To determine the infrared (IR) bands and shifts related to PVA, starch, urea, sugar, and molasses interaction, it is well known that hydrogen bonding or other interactions between chemical groups on dissimilar polymers should theoretically cause a shift in peak position of the participating groups [53]. In Figure 4 the FTIR spectra of urea incorporated St/PVA/Ac based film show several peaks; $-\mathrm{NH} /-\mathrm{OH}$ overlapping band appears at range of 3600$3200 \mathrm{~cm}^{-1}$ and at $2934 \mathrm{~cm}^{-1}$ for $-\mathrm{CH}$ stretching vibration. In case of urea based film, a broad peak appears at $1631.95 \mathrm{~cm}^{-1}$. In this region the amide absorption band takes place. The broadness of the peak shows that the $\mathrm{C}=\mathrm{C}$ absorption band has overlapped with amide band. The absorption bands at $1450 \mathrm{~cm}^{-1}$ correspond to $-\mathrm{CH}_{3}$ bending vibration, $\mathrm{C}-\mathrm{O}$ stretching vibration in $\mathrm{C}-\mathrm{O}-\mathrm{C}$ ring system is observed at $1085 \mathrm{~cm}^{-1}$, and $\mathrm{C}-\mathrm{O}$ and $\mathrm{C}-\mathrm{C}$ absorption bands are coupled in this frequency. C-O-C ring of starch is vibrated at $931 \mathrm{~cm}^{-1}$ and $=\mathrm{C}-\mathrm{H}$ out of plane bending appears at $852 \mathrm{~cm}^{-1}$. Small differences were observed after incorporation of sugar in the St/PVA/Ac based film. Indeed, an absorption band can be observed at $3335 \mathrm{~cm}^{-1}$ after starch and sugar addition, related to the typical hydrogen bound $\mathrm{O}-\mathrm{H}$ vibration of semicrystalline starch and sugar. A characteristic peak of $-\mathrm{CH}$ stretching vibration appeared at $2931 \mathrm{~cm}^{-1}$ and at $1638 \mathrm{~cm}^{-1}$ for stretching vibration of $\mathrm{C}=\mathrm{C}$; a medium intensity $-\mathrm{CH}_{3}$ bending vibration appears at $1420 \mathrm{~cm}^{-1}$, and C$\mathrm{O}$ stretching vibration in $\mathrm{C}-\mathrm{O}-\mathrm{C}$ ring system is observed at $1026 \mathrm{~cm}^{-1}$, and $\mathrm{C}-\mathrm{O}$ and $\mathrm{C}-\mathrm{C}$ absorption bands are coupled in this frequency. C-O-C ring of starch vibrated at $930 \mathrm{~cm}^{-1}$ and $=\mathrm{C}-\mathrm{H}$ out of plane bending appears at $853 \mathrm{~cm}^{-1}$.

The FTIR spectra of St/PVA/Ac/molasses film show little differences from other two spectra. The hydrogen bonded $-\mathrm{OH}$ vibration shifted to slightly lower frequency at $3332 \mathrm{~cm}^{-1}$ than sugar at $3335 \mathrm{~cm}^{-1}$. The hydrogen bonded $-\mathrm{O}-\mathrm{H}$ stretching appeared at lower frequency, because

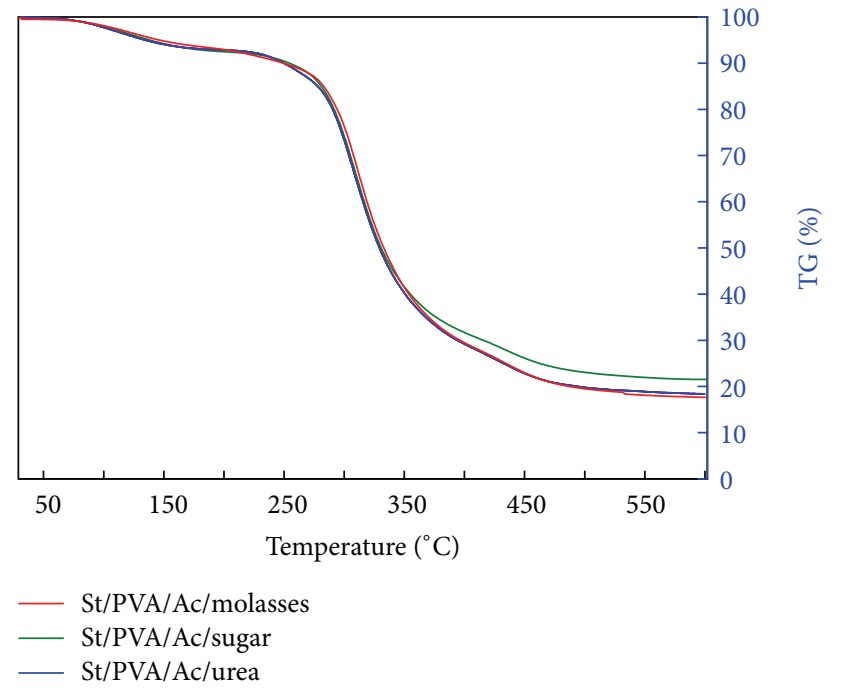

Figure 5: Thermogravimetry of St/PVA/Ac/urea, St/PVA/Ac/sugar, and St/PVA/Ac/molasses based films.

the hydrogen bond as a resonance hybrid is weakened, its force constant is reduced, and therefore the stretching frequency is lowered. The $-\mathrm{CH}$ stretching vibration appears at $2932 \mathrm{~cm}^{-1}$, stretching vibration of $\mathrm{C}=\mathrm{C}$ at $1650 \mathrm{~cm}^{-1}$, and $-\mathrm{CH}_{3}$ bending vibration at $1420 \mathrm{~cm}^{-1}$; $\mathrm{C}-\mathrm{O}$ stretching vibration in $\mathrm{C}-\mathrm{O}-\mathrm{C}$ ring system is observed at $1025 \mathrm{~cm}^{-1}$ and strong intensity $=\mathrm{C}-\mathrm{H}$ out of plane bending appears at $852 \mathrm{~cm}^{-1}$.

\subsection{Effect of Thermal Properties of Urea, Sugar, and Molasses Incorporated St/PVA/Ac Based Film}

3.4.1. TG. Figure 5 represents the thermogravimetry (TG) of $\mathrm{St} / \mathrm{PVA} / \mathrm{Ac} /$ urea, St/PVA/Ac/molasses, and St/PVA/Ac/sugar films and they showed a two-step weight loss zone. In the St/PVA/Ac/urea based film, the onset of melting occurred at 


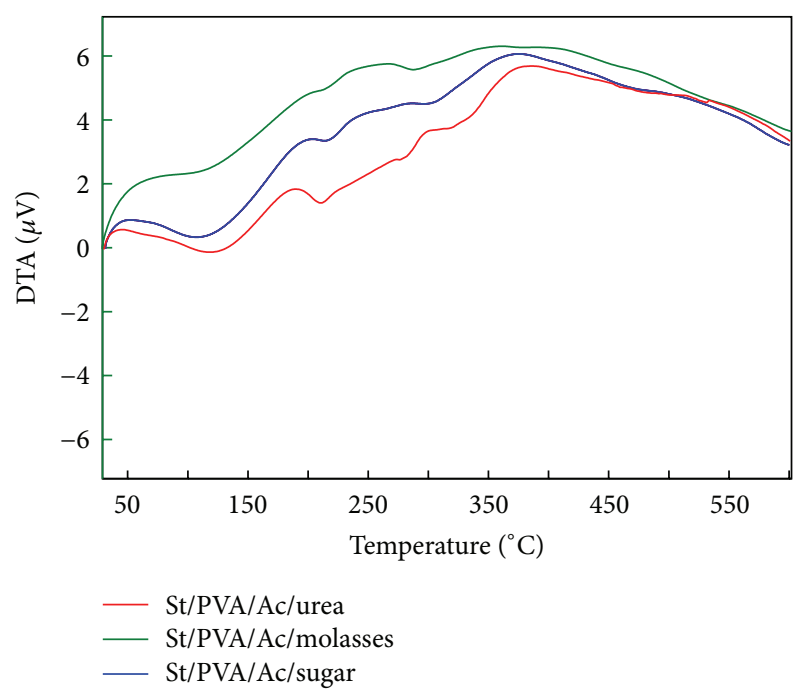

FIGURE 6: Differential thermal analysis of St/PVA/Ac/urea, St/PVA/ Ac/sugar, and St/PVA/Ac/molasses films.

$287^{\circ} \mathrm{C}$ where the film lost its $12 \%$ weight and the offset of melting occurred at $350^{\circ} \mathrm{C}$ and it degraded its $70 \%$ weight and $60 \%$ degradation took place at $318^{\circ} \mathrm{C}$. In the St/PVA/Ac/sugar film the onset of melting occurred at $280^{\circ} \mathrm{C}$ where the film lost its $10 \%$ weight and offset of melting occurred at $360^{\circ} \mathrm{C}$ and it degraded its $79 \%$ weight and $60 \%$ degradation took place at around $309^{\circ} \mathrm{C}$ temperature. Again in the St/PVA/Ac/molasses film the onset of melting occurred at $281^{\circ} \mathrm{C}$ where the film lost its $9 \%$ weight and the offset of melting occurred at $344^{\circ} \mathrm{C}$ and it degraded its $64 \%$ weight and $60 \%$ degradation took place at $312^{\circ} \mathrm{C}$ temperature. The first step of weight loss in every film could be attributed to the loss of loosely bound water. The second step was mainly caused by the heat decomposition of the molecules, and the products were composed of small molecular carbon and hydrocarbon. High molecule weight starch and the crystalline starch of PVA and starch are decomposed within this stage [36]. Sugar and molasses incorporated film shows higher stability than urea which is also supported by their mechanical property. The incorporation of urea highly reduces the degradation temperature of St/PVA/Ac blends than sugar and molasses incorporated film.

3.4.2. DTA. Figure 6 depicts the differential thermal analysis (DTA) of St/PVA/Ac/urea, St/PVA/Ac/molasses, and St/PVA/ Ac/sugar films. The DTA curve of St/PVA/Ac/Urea shows two endothermic peaks at $130^{\circ} \mathrm{C}(-0.05 \mathrm{uV})$ and at $317^{\circ} \mathrm{C}$ $(3.74 \mathrm{uV})$, which indicate the melting and decomposition temperature, respectively. The incorporation of sugar in the St/PVA/Ac film depicts the melting point and decomposition temperature and it occurred at $107^{\circ} \mathrm{C}(0.33 \mathrm{uV})$ and at $304^{\circ} \mathrm{C}$ $(4.54 \mathrm{uV})$. Again, the DTA curve of the St/PVA/Ac/molasses film shows its melting point and decomposition point at $107^{\circ} \mathrm{C}(2.36 \mathrm{uV})$ and at $308^{\circ} \mathrm{C}(5.8 \mathrm{uV})$, respectively.

3.4.3. DTG. Figure 7 represents the differential thermogravimetry (DTG) of St/PVA/Ac/urea, St/PVA/Ac/molasses, and

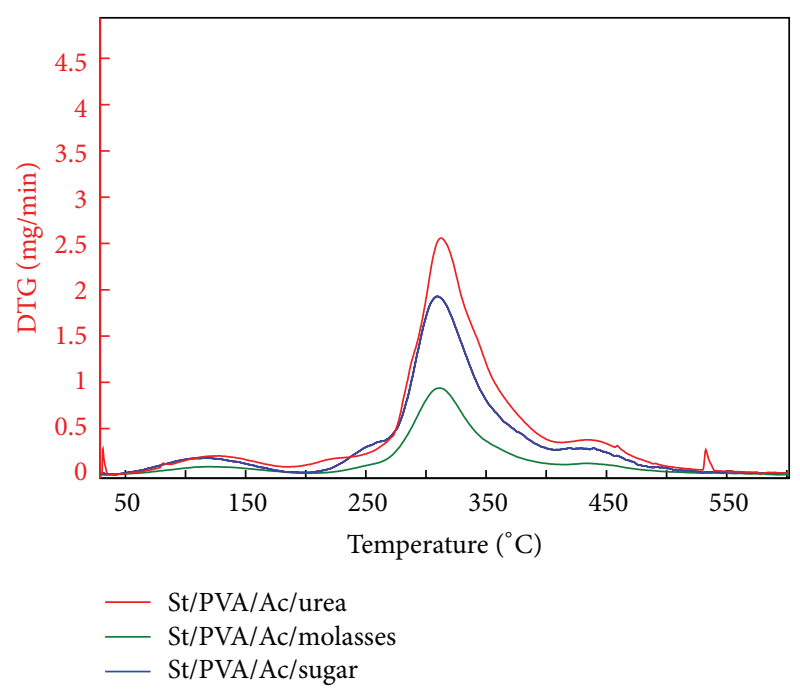

FIGURE 7: Differential thermogravimetry of St/PVA/Ac/urea, St/ PVA/Ac/sugar, and St/PVA/Ac/molasses based films.

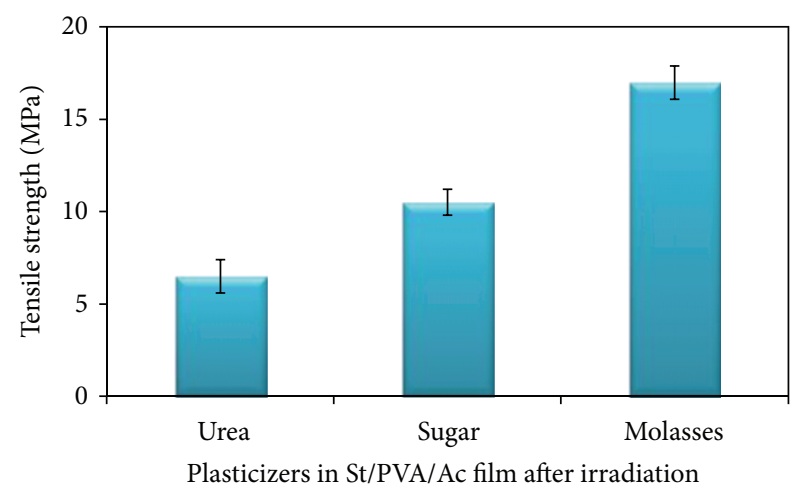

FIGURE 8: Effects of urea, sugar, and molasses on the TS of St/PVA/ Ac blend film after irradiation.

$\mathrm{St} / \mathrm{PVA} / \mathrm{Ac} /$ sugar films. From this figure it is clearly understood that the incorporation of urea lowers the thermal stability much higher in comparison to all of plasticizers, which also supports the mechanical property of the plasticizer incorporated films. The DTG curve of the starch/PVA/Ac/urea based film depicts one predominant peak at $313^{\circ} \mathrm{C}$, where the maximum degradation rate was $2.556 \mathrm{mg} / \mathrm{min}$. DTG curve of the starch/PVA/Ac/sugar based film depicts the predominant peak at $309^{\circ} \mathrm{C}$, where the maximum degradation rate was $1.924 \mathrm{mg} / \mathrm{min}$; when molasses incorporated into the St/PVA/Ac film the degradation rate was lowered to $0.935 \mathrm{mg} / \mathrm{in}$ at $310^{\circ} \mathrm{C}$ temperature.

3.5. Effect of TS and EB of Urea, Sugar and Molasses Incorporated St/PVA/Ac Based Film after Irradiation. Figures 8 and 9 illustrate the TS and EB of irradiated St/PVA/Ac/urea, St/PVA/Ac/sugar, and St/PVA/Ac/molasses films. After irradiation the TS of those films shows changes to some extent. However, the EB shows remarkable change. The TS of irradiated urea is $6.5 \pm 0.9 \mathrm{MPa}$ and the $\mathrm{EB}$ is $59 \pm 0.9 \%$, whereas in the non-irradiated film the TS and the EB have been found 


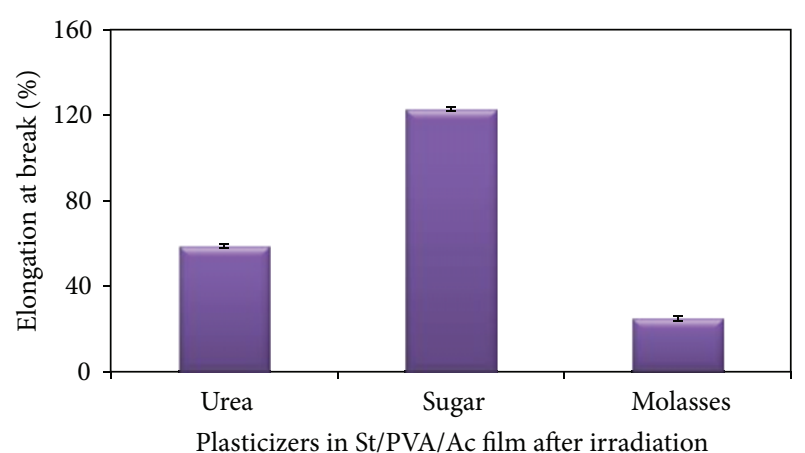

FIGURE 9: Effects of urea, sugar, and molasses on the EB of St/PVA/ Ac blend film after irradiation.

to be $5 \pm 0.26 \mathrm{MPa}$ and $126.5 \pm 0.9 \%$, respectively. Again irradiated St/PVA/Ac/molasses film shows TS of $17 \pm 0.9 \mathrm{MPa}$ and $25 \pm 1 \% \mathrm{~EB}$, but the non-irradiated molasses incorporated film shows TS of $15 \pm 0.89 \mathrm{MPa}$ and $59 \pm 0.9 \% \mathrm{~EB}$. The behavior of both urea and molasses can be explained as radiation dose produces a denser network structure because of increased cross-linking that leads to the enhancement of mechanical properties such as TS, hardness and softening temperature in association with reduced EB [52]. In the non-irradiated sugar incorporated film the TS and EB were $16 \pm 0.5 \mathrm{MPa}$ and $13 \pm 0.7 \%$, respectively, but the irradiated St/PVA/Ac/sugar film shows decreased TS of $10.5 \pm 0.7 \mathrm{MPa}$ and enormously high elongation property which corresponds to $123 \pm 1.1 \%$. This can be explained by the different characteristic properties of radiation dose because radiation sometimes leads to chain scission which ultimately weakens the tensile property while increasing the flexibility.

\subsection{Effect of Thermal Properties of Urea, Sugar, and Molasses Incorporated St/PVA/Ac Based Film after Irradiation}

3.6.1. TG. Figure 10 represents the thermo gravimetry (TG) of irradiated St/PVA/Ac/urea, St/PVA/Ac/molasses, and St/ $\mathrm{PVA} / \mathrm{Ac} /$ sugar films. In the irradiated St/PVA/Ac/urea based film, the onset of melting occurred at $288^{\circ} \mathrm{C}$ where the film lost its $11 \%$ weight and the offset of melting occurred at $358^{\circ} \mathrm{C}$ and it degraded its $76 \%$ weight and $60 \%$ degradation took place at $323^{\circ} \mathrm{C}$. In the irradiated St/PVA/Ac/sugar film the onset of melting occurred at $278^{\circ} \mathrm{C}$ where the film lost its $10 \%$ weight and offset of melting occurred at $363^{\circ} \mathrm{C}$ and it degraded its $76 \%$ weight and $60 \%$ degradation took place at around $321^{\circ} \mathrm{C}$ temperature. Again in the irradiated St/ $\mathrm{PVA} / \mathrm{Ac} / \mathrm{molasses}$ film the onset of melting occurred at $281^{\circ} \mathrm{C}$ where the film lost its $10 \%$ weight and the offset of melting occurred at $351^{\circ} \mathrm{C}$ where it degraded its $67 \%$ weight and $60 \%$ degradation took place at $316^{\circ} \mathrm{C}$ temperature.

3.6.2. DTA. Figure 11 depicts the differential thermal analysis (DTA) of irradiated St/PVA/Ac/urea, St/PVA/Ac/molasses, and St/PVA/Ac/sugar films. The DTA curve of irradiated $\mathrm{St} / \mathrm{PVA} / \mathrm{Ac} / \mathrm{urea}$ shows two endothermic peaks at $125^{\circ} \mathrm{C}$ $(-0.63 \mathrm{uV})$ and at $313^{\circ} \mathrm{C}(2.87 \mathrm{uV})$, which indicate the melting

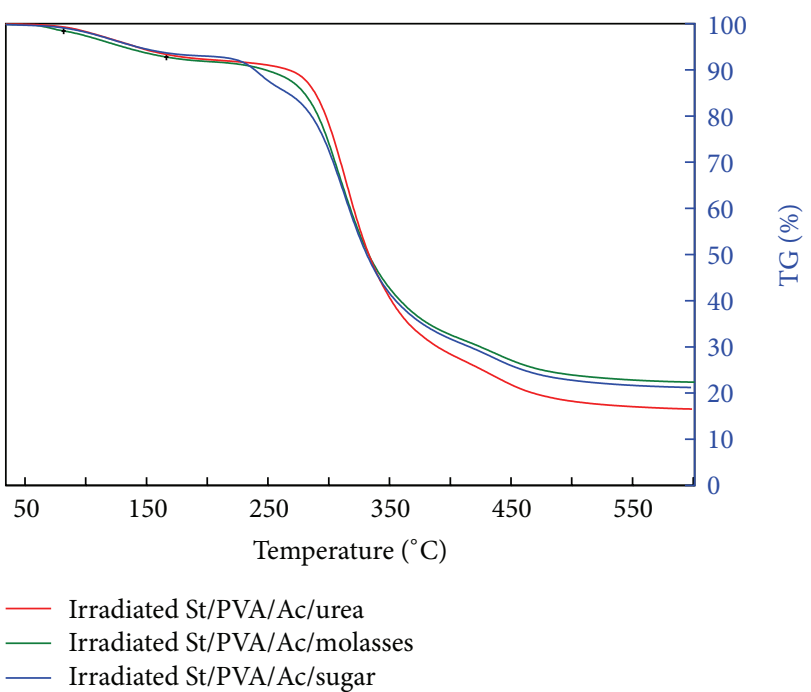

FIGURE 10: Thermo gravimetry of irradiated St/PVA/Ac/urea, St/ PVA/Ac/sugar, and St/PVA/Ac/molasses based films.

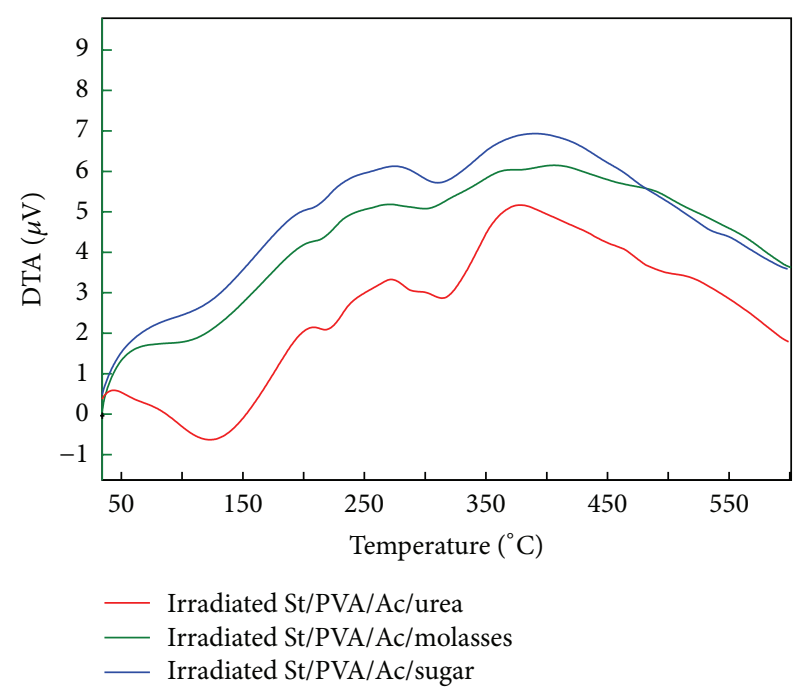

FIGURE 11: Differential thermal analysis of irradiated St/PVA/Ac/ urea, St/PVA/Ac/sugar, and St/PVA/Ac/molasses based films.

and decomposition temperature, respectively. The irradiated St/PVA/Ac/Sugar film depicts the melting point and decomposition temperature and it occurred at $124^{\circ} \mathrm{C}(2.81 \mathrm{uV})$ and at $310^{\circ} \mathrm{C}(5.72 \mathrm{uV})$, respectively. Again, the DTA curve of the St/PVA/Ac/molasses film shows their melting point and decomposition point at $104^{\circ} \mathrm{C}(1.81 \mathrm{uV})$ and at $306^{\circ} \mathrm{C}$ $(5.11 \mathrm{uV})$.

3.6.3. DTG. Figure 12 represents the differential thermo gravimetry (DTG) of irradiated St/PVA/Ac/urea, St/PVA/Ac/ molasses, and St/PVA/Ac/sugar films. The DTG curve of the irradiated St/PVA/Ac/Urea based film depicts one predominant peak at $316^{\circ} \mathrm{C}$, where the maximum degradation rate was found to be $2.702 \mathrm{mg} / \mathrm{min}$. DTG curve of the irradiated St/PVA/Ac/sugar based film depicts the predominant 


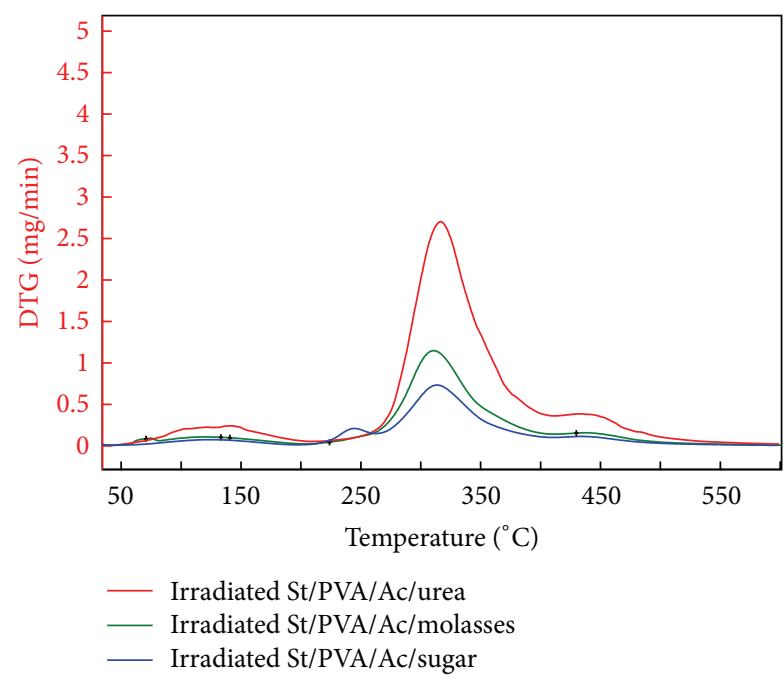

FIGURE 12: Differential thermo gravimetry of irradiated St/PVA/ Ac/urea, St/PVA/Ac/sugar, and St/PVA/Ac/molasses based films.

peak at $315^{\circ} \mathrm{C}$, where the maximum degradation rate was $0.731 \mathrm{mg} / \mathrm{min}$; however, when molasses was incorporated into the film, the degradation rate was $1.143 \mathrm{mg} / \mathrm{min}$ at $309^{\circ} \mathrm{C}$ temperature.

3.7. Effect of Water Absorption of Nonirradiated and Irradiated St/PVA/Ac/Urea, St/PVA/Ac/Sugar and St/PVA/Molasses Films. Figure 13 represents the water absorption curve of the Irradiated and non-irradiated urea, sugar, and molasses incorporated St/PVA/Ac based film for 60 minutes. From the figure it has been observed that urea incorporated film shows the lowest absorption tendency both in irradiated and non-irradiated conditions than others, whereas sugar and molasses treated films show increased water absorption behavior. From the figure it has also been found that in the film of both urea and molasses, the irradiated film shows lower water absorption behavior than non-irradiated film. However, different behavior was observed in the case of sugar incorporated film. Irradiated sugar incorporated film shows higher water absorption tendency than non-irradiated film.

Water uptake was measured by soaking the films in static glass beakers containing deionized water at room temperature $\left(25^{\circ} \mathrm{C}\right)$ for different time series $(1,3,5,10,20,40$, and 60 minutes). Urea incorporated film shows reduced water uptake property than others. It is shown that at the beginning, St/PVA/Ac/urea based film absorbs 101\% water in the first minute and continues to absorb water up to 10 minutes and from 20 minutes the film lost its weight slightly into water. Yet again, the irradiated St/PVA/Ac/urea based film absorbs less water than the non-irradiated film. In the first minute it absorbs only $74 \%$ water compared to $101 \%$ absorbed by non-irradiated film. The water uptake curve showed steady behavior and the irradiated film was more stable in water and was still absorbing water up to 60 minutes. This may be due to the formation of cross-linking; polysaccharide chain of starch and $-\mathrm{OH}$ (as functional groups) of PVA and urea create a three dimensional compact structure. Therefore, there is very little chance for the water molecule to be associated or absorbed within the irradiated film. Thus, the irradiated samples showed less water uptake.

The sugar incorporated St/PVA/Ac based film absorbs $130 \%$ water after first minute of immersion and increases absorption with increase in soaking time. After 60 minutes it lost its weight in water. After gamma irradiation, the sugar incorporated film showed slightly higher water uptake. This is because after gamma radiation at $200 \mathrm{krad}$, the polymeric chain structure of the film has undergone degradation and the compactness of the film has decreased. Intermolecular hydrogen bonding between the hydrocarbons groups of starch and PVA and sugar side chain favors the water absorption in the film [36].

After adding molasses in the St/PVA/Ac based film, water uptake property was decreased. This is may be due to the presence of sufficient intermolecular hydrogen bonding between the hydrocarbons groups of starch and PVA and molasses side chain. Molasses contain organic constituent, that is, sugar and nonsugar (insoluble) and inorganic constituents ( $\mathrm{CaO}, \mathrm{MgO}$, etc.). These components may slightly restrict the St/PVA/Ac/Molasses films to gain water [44]. For this reason molasses incorporated film was more stable in water and continued to absorb water up to 60 minutes. On the other hand, irradiated St/PVA/Ac/Molasses incorporated film absorbs more water (128\%) in 1 minute immersion than non-irradiated film (90\%). But after increasing soaking time, the film absorbs less water than non-irradiated film and it lost its weight into water.

3.8. Comparison of Soil Biodegradability of Nonirradiated and Irradiated Films. Figure 14 shows the comparison of soil biodegradability of non-irradiated and irradiated St/PVA/Ac/ urea, St/PVA/Ac/sugar, and St/PVA/Ac/molasses films. These films were buried into the soil to study the degradation trend. The films were weighed individually and buried in garden soil for 1 to 70 days. Moisture content of the soil was maintained at around $15 \%-18 \%$. After these periods, the films were withdrawn cautiously from the soil, washed, dried, and reweighed. At the end, the weight loss of the samples was calculated. From the figure it has been found that molasses incorporated films (both non-irradiated and irradiated) were degraded to $100 \%$ in 70 days. Though the irradiated film of molasses degrades at a slower rate than the non-irradiated film from 1 to 21 days and from the 49th day, each film began to degrade equally. Irradiated urea incorporated film shows lower degradation rate than the non-irradiated film, while irradiated sugar incorporated films degrade faster than nonirradiated films.

At initial stage the biodegradation rate was higher. The weight loss is influenced by the composition of the blend and by the nature of the microorganisms. The highest values of weight loss were obtained due to the high content of starch. During biodegradation, spherical holes appear due to colonization by the degrading microorganisms. The starch and edible plasticizers are first consumed by microorganisms, together with the amorphous part of PVA. When the starch was almost fully degraded, the PVA was also further degraded, but its speed was slower than that of the starch 


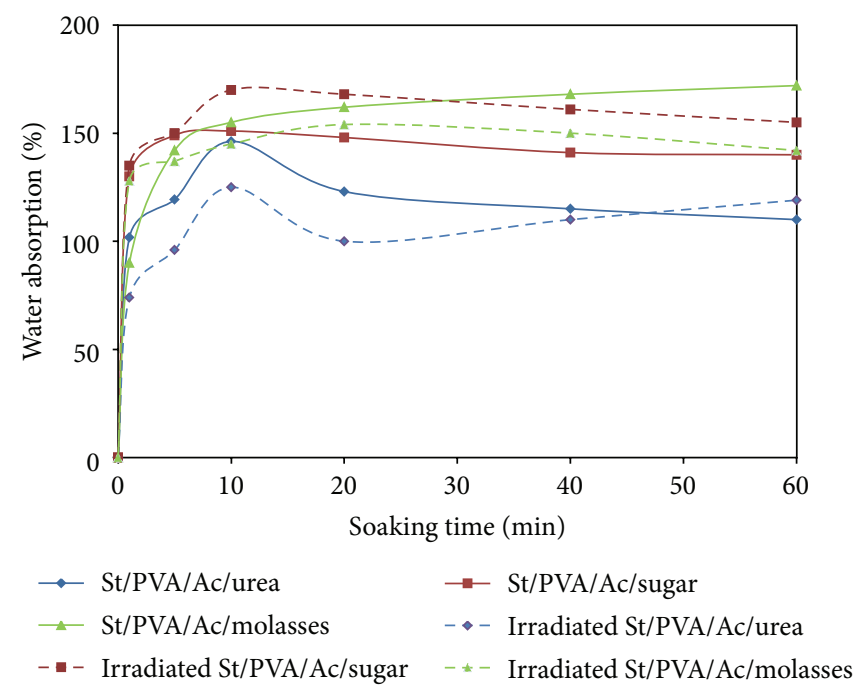

FIGURE 13: Effect of water absorption of non-irradiated and irradiated St/PVA/Ac/urea, St/PVA/Ac/sugar, and St/PVA/molasses films.

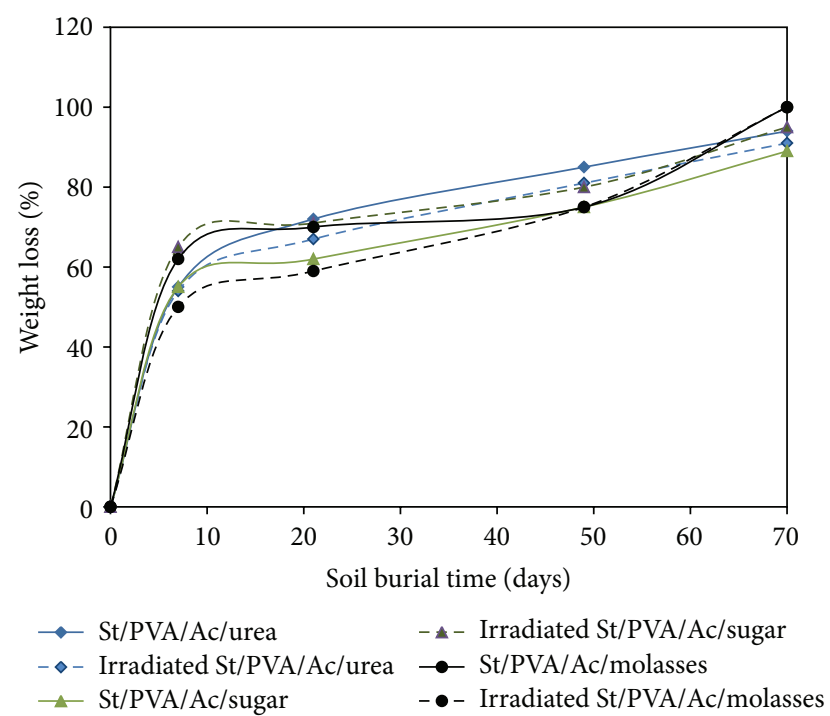

FIGURE 14: Soil biodegradability of urea, sugar, and molasses incorporated St/PVA/Ac based film both at irradiated and non-irradiated conditions.

molecule [54]. The weak biodegradability of PVA could be partly caused by the structure of the PVA (unknown stereoregularity of hydroxyl groups) or by the degree of polymerization (comparatively high molecular weight). From Figure 14 it has been observed that urea incorporated film degraded faster than irradiated film. At 7 days, irradiated film loss was $54 \%$ and the non-irradiated film loss was $55 \%$ after 21 days the weight loss reached $67 \%$ for the former and $72 \%$ for the latter. Finally after 70 days of burial time irradiated film loss was $91 \%$ and the non-irradiated film loss was $94 \%$. The degradability of the gamma-irradiated film was slightly lower than that of the non-radiated film, as because of cross-linking, the gamma-irradiated film produces a compact structure, which degraded at a lower speed. This trend was also found in molasses incorporated film; the irradiated molasses incorporated film degraded slower (59\%) than non-irradiated film $(70 \%)$ up to 21 days and both films degraded at the same rate $(75 \%)$ after 7 -week soil burial time and decomposed $100 \%$ after 10 weeks. This may be due to the excessive presence of microorganisms in the soil as well as molasses which attract those microbes habitually [54]. On the other hand, the irradiated sugar incorporated film degrades faster than nonirradiated film. At the end of one week, the non-irradiated sugar incorporated film shows weight loss of $55 \%$ and the irradiated film shows weight loss of $65 \%$. After 3 weeks the non-irradiated film degrades to $62 \%$ and the irradiated film degrades to $71 \%$. After 70 days of soil burial time the former lost $89 \%$ and the latter lost $95 \%$ of weight. This can be explained by the different characteristic properties of radiation dose because radiation for a certain time leads to chain scission, which helps to degrade the film more quickly. So, from the soil burial test it has been observed that the molasses incorporated films (both non-irradiated and irradiated) show maximum biodegradation. Similar results were also found for other film.

\section{Conclusion}

This study indicated that a fully biodegradable and higher TS containing St/PVA based film could be achieved by incorporation of Acacia catechu extract, as a natural polyphenol. Biodegradable St/PVA/Ac blend based films were successfully prepared by solution casting. The optimized $0.5 \%$ Ac extracts incorporated St/PVA based film was treated with $10 \%$ urea, $10 \%$ sugar, and $10 \%$ molasses individually to observe the effect of different plasticizers at both irradiated and nonirradiated conditions. It has been observed that at nonirradiated condition St/PVA/Ac/molasses based film showed the highest TS $(15 \pm 0.89 \mathrm{MPa})$ and EB $(59 \pm 0.9 \%)$ which was also verified by TGA analysis. However, at $200 \mathrm{krad}$ radiation dose, St/PVA/Ac/sugar film shows optimum results (TS: $10.5 \pm 0.7 \mathrm{MPa}$ and EB: $123 \pm 1.1 \%$ ). The thermal analyses also support this trend. The FTIR of each film has 
been carried out effectively. The most desirable property of a biodegradable film is the soil burial test which also has been carried out for every film separately and successfully. The biodegradability test shows amazing results for almost every film and it has been found that after 70 days of soil burial, the St/PVA/Ac/molasses film (both irradiated and nonirradiated) degrades to $100 \%$, whereas the irradiated urea incorporated film degrades to $91 \%$ and the non-irradiated one degrades to $94 \%$. Again, non-irradiated sugar incorporated film lost its $89 \%$ weight and the irradiated film lost $95 \%$ weight after 70 days of soil burial time.

\section{Conflict of Interests}

There is no conflict of interests.

\section{Acknowledgment}

The authors thank the staff of Institute of Radiation and Polymer Technology, Bangladesh Atomic Energy Commission, for their technical support and advice throughout the work.

\section{References}

[1] R. Shi, J. Bi, Z. Zhang et al., "The effect of citric acid on the structural properties and cytotoxicity of the polyvinyl alcohol/ starch films when molding at high temperature," Carbohydrate Polymers, vol. 74, no. 4, pp. 763-770, 2008.

[2] R. W. Lenz, "Biodegradable polymers," Advances in Polymer Sciences, vol. 107, pp. 1-40, 1993.

[3] G. M. Glenn and J. Hsu, "Compression-formed starch-based plastic," Industrial Crops and Products, vol. 7, no. 1, pp. 37-44, 1997.

[4] M. E. Gomes, A. S. Ribeiro, P. B. Malafaya, R. L. Reis, and A. M. Cunha, "A new approach based on injection moulding to produce biodegradable starch-based polymeric scaffolds: morphology, mechanical and degradation behaviour," Biomaterials, vol. 22, no. 9, pp. 883-889, 2001.

[5] A. R. Kirby, S. A. Clark, R. Parker, and A. C. Smith, “The deformation and failure behaviour of wheat starch plasticized with water and polyols," Journal of Materials Science, vol. 28, no. 21, pp. 5937-5942, 1993.

[6] A. L. Ollett, R. Parker, and A. C. Smith, "Deformation and fracture behaviour of wheat starch plasticized with glucose and water," Journal of Materials Science, vol. 26, no. 5, pp. 1351-1356, 1991.

[7] A. Sen and M. Bhattacharya, "Residual stresses and density gradient in injection molded starch/synthetic polymer blends," Polymer, vol. 41, no. 26, pp. 9177-9190, 2000.

[8] J. J. G. van Soest and D. B. Borger, "Structure and properties of compression-molded thermoplastic starch materials from normal and high-amylose maize starches," Journal of Applied Polymer Science, vol. 64, no. 4, pp. 631-644, 1997.

[9] K. E. Spence, J. L. Jane, and A. L. Pometto, "Dialdehyde starch and zein plastic: mechanical properties and biodegradability," Journal of Environmental Polymer Degradation, vol. 3, no. 2, pp. 69-74, 1995.

[10] Y. Nakayama, M. Takatsuka, and T. Matsuda, "Surface hydrogelation using photolysis of dithiocarbamate or xanthate: hydrogelation, surface fixation, and bioactive substance immobilization," Langmuir, vol. 15, no. 5, pp. 1667-1672, 1999.
[11] S. H. Imam, P. Cinelli, S. H. Gordon, and E. Chiellini, "Characterization of biodegradable composite films prepared from blends of poly(vinyl alcohol), cornstarch, and lignocellulosic fiber," Journal of Polymers \& the Environment, vol. 13, no. 1, pp. 47-55, 2005.

[12] H. Jiang, G. Campbell, D. Boughner, W. K. Wan, and M. Quantz, "Design and manufacture of a polyvinyl alcohol (PVA) cryogel tri-leaflet heart valve prosthesis," Medical Engineering and Physics, vol. 26, no. 4, pp. 269-277, 2004.

[13] W. K. Wan, G. Campbell, Z. F. Zhang, A. J. Hui, and D. R. Boughner, "Optimizing the tensile properties of polyvinyl alcohol hydrogel for the construction of a bioprosthetic heart valve stent," Journal of Biomedical Materials Research, vol. 63, no. 6, pp. 854-861, 2002.

[14] S. D. Yoon, S. H. Chough, and H. R. Park, "Preparation of resistant starch/poly(vinyl alcohol) blend films with added plasticizer and crosslinking agents," Journal of Applied Polymer Science, vol. 106, no. 4, pp. 2485-2493, 2007.

[15] Y. Watanabe, M. Morita, N. Hamade, and Y. Tsujisake, "Formation of hydrogen peroxide by a polyvinyl alcohol degrading enzyme," Journal of Agriculture Biology and Chemistry, vol. 39, no. 12, pp. 2447-2448, 1975.

[16] M. Morita and Y. Watanabe, "A secondary alcohol oxidase: a component of a polyvinyl alcohol degrading enzyme preparation," Agricultural and Biological Chemistry, vol. 41, no. 8, pp. 1535-1537, 1977.

[17] P. Cinelli, E. Chiellini, J. W. Lawton, and S. H. Imam, "Foamed articles based on potato starch, corn fibers and poly(vinyl alcohol)," Polymer Degradation and Stability, vol. 91, no. 5, pp. 1147-1155, 2006.

[18] R. B. Siddaramaiah and R. Somashekar, "Structure-property relation in polyvinyl alcohol/starch composites," Journal of Applied Polymer Science, vol. 91, no. 1, pp. 630-635, 2004.

[19] Y. U. Nabar, D. Draybuck, and R. Narayan, "Physicomechanical and hydrophobic properties of starch foams extruded with different biodegradable polymers," Journal of Applied Polymer Science, vol. 102, no. 1, pp. 58-68, 2006.

[20] D. Demirgöz, C. Elvira, J. F. Mano, A. M. Cunha, E. Piskin, and R. L. Reis, "Chemical modification of starch based biodegradable polymeric blends: effects on water uptake, degradation behaviour and mechanical properties," Polymer Degradation and Stability, vol. 70, no. 2, pp. 161-170, 2000.

[21] S. Kiatkamjornwong, P. Thakeow, and M. Sonsuk, "Chemical modification of cassava starch for degradable polyethylene sheets," Polymer Degradation and Stability, vol. 73, no. 2, pp. 363-375, 2001.

[22] M. Kim, "Evaluation of degradability of hydroxypropylated potato starch/polyethylene blend films," Carbohydrate Polymers, vol. 54, no. 2, pp. 173-181, 2003.

[23] M. Kim and S. J. Lee, "Characteristics of cross-linked potato starch and starch- filled linear, low-density polymer films," Carbohydrate Polymers, vol. 50, no. 4, pp. 331-337, 2002.

[24] I. M. Thakore, S. Desai, B. D. Sarawade, and S. Devi, "Studies on biodegradability, morphology and thermo-mechanical properties of LDPE/modified starch blends," European Polymer Journal, vol. 37, no. 1, pp. 151-160, 2001.

[25] Y. Xu, V. Miladinov, and M. A. Hanna, "Synthesis and characterization of starch acetates with high drgree of substitution," Cereal Chemistry, vol. 81, no. 6, pp. 735-740, 2004.

[26] G. Zhao, Y. Liu, C. Fang, M. Zang, C. Zhou, and Z. Chen, "Water resistance, mechanical properties and biodegradability 
of methylated corn starch/poly (vinyl alcohol) blend film," Journal of Polymer Degradation and Stability, vol. 91, no. 4, pp. 703-711, 2006.

[27] M. K. Beliakova, A. A. Aly, and F. A. Abdel-Mohdy, "Grafting of poly(methacrylic acid) on starch and poly(vinyl alcohol)," Starch/Staerke, vol. 56, no. 9, pp. 407-412, 2004.

[28] R. Jayasekara, I. Harding, I. Bowater, G. B. Y. Christie, and G. T. Lonergan, "Preparation, surface modification and characterisation of solution cast starch PVA blended films," Polymer Testing, vol. 23, no. 1, pp. 17-27, 2004.

[29] B. Ramaraj, "Crosslinked poly(vinyl alcohol) and starch composite films. II. Physicomechanical, thermal properties and swelling studies," Journal of Applied Polymer Science, vol. 103, no. 2, pp. 909-916, 2007.

[30] Y. Yin, J. Li, Y. Liu, and Z. Li, "Starch crosslinkrd with poly (vinyl alcohol) by boric acid," Journal of Applied Polymer Science, vol. 96, no. 4, pp. 1394-1397, 2005.

[31] B. Sreedhar, D. K. Chattopadhyay, M. S. H. Karunakar, and A. R. K. Sastry, "Thermal and surface characterization of plasticized starch polyvinyl alcohol blends crosslinked with epichlorohydrin," Journal of Applied Polymer Science, vol. 101, no. 1, pp. 2534, 2006.

[32] M. Zhai, F. Yoshii, and T. Kume, "Radiation modification of starch-based plastic sheets," Carbohydrate Polymers, vol. 52, no. 3, pp. 311-317, 2003.

[33] N. Follain, C. Joly, P. Dole, and C. Bliard, "Properties of starch based blends. Part 2. Influence of poly vinyl alcohol addition and photocrosslinking on starch based materials mechanical properties," Carbohydrate Polymers, vol. 60, no. 2, pp. 185-192, 2005.

[34] S. S. Bhatnagar, The Weakth of India, C.S.I.R, New Delhi, India, 1948.

[35] U. Siripatrawan and B. R. Harte, "Physical properties and antioxidant activity of an active film from chitosan incorporated with green tea extract," Food Hydrocolloids, vol. 24, no. 8, pp. 770-775, 2010.

[36] F. Parvin, M. A. Khan, A. H. M. Saadat et al., "Preparation and characterization of gamma irradiated sugar containing starch/ poly (vinyl alcohol)- based blend films," Journal of Polymers \& the Environment, vol. 19, no. 4, pp. 1013-1022, 2011.

[37] R. A. Talja, H. Helén, Y. H. Roos, and K. Jouppila, "Effect of various polyols and polyol contents on physical and mechanical properties of potato starch-based films," Carbohydrate Polymers, vol. 67, no. 3, pp. 288-295, 2007.

[38] R. A. Talja, H. Helén, Y. H. Roos, and K. Jouppila, “Effect of type and content of binary polyol mixtures on physical and mechanical properties of starch-based edible films," Carbohydrate Polymers, vol. 71, no. 2, pp. 269-276, 2008.

[39] C. H. Chen and L. S. Lai, "Mechanical and water vapor barrier properties of tapioca starch/decolorized hsian-tsao leaf gum films in the presence of plasticizer," Food Hydrocolloids, vol. 22, no. 8, pp. 1584-1595, 2008.

[40] D. F. Parraa, C. C. Tadinib, P. Poncea, and A. B. Lugaoa, "Mechanical properties and water vapor transmission in some blends of cassava starch edible films," Carbohydrate Polymers, vol. 58, no. 4, pp. 475-481, 2004.

[41] A. Bhattacharya, "Radiation and industrial polymer," Progress in Polymer Science, vol. 25, no. 3, pp. 371-401, 2000.

[42] J. Gehring, "With radiation crosslinking of engineering plastics into the next millennium," Radiation Physics and Chemistry, vol. 57, no. 3-6, pp. 361-365, 2000.
[43] M. Zhai, F. Yoshii, and T. Kume, "Radiation modification of starch-based plastic sheets," Carbohydrate Polymers, vol. 52, no. 3, pp. 311-317, 2003.

[44] H. Olbrich, The Molasses, Biotechnologie-Kempe GmbH, Berlin, Germany, 2006.

[45] H. Tang, H. Xiong, S. Tang, and P. Zou, "A starch-based biodegradable film modified by nano silicon dioxide," Journal of Applied Polymer Science, vol. 113, no. 1, pp. 34-40, 2009.

[46] S. Rohn, H. M. Rawel, and J. Kroll, "Antioxidant activity of protein-bound quercetin," Journal of Agricultural and Food Chemistry, vol. 52, no. 15, pp. 4725-4729, 2004.

[47] J. Gómez-Estaca, B. Giménez, P. Montero, and M. C. GómezGuillén, "Incorporation of antioxidant borage extract into edible films based on sole skin gelatin or a commercial fish gelatin," Journal of Food Engineering, vol. 92, no. 1, pp. 78-85, 2009.

[48] M. C. Gómez-Guillén, M. Ihl, V. Bifani, A. Silva, and P. Montero, "Edible films made from tuna-fish gelatin with antioxidant extracts of two different murta ecotypes leaves (Ugni molinae Turcz)," Food Hydrocolloids, vol. 21, no. 7, pp. 1133-1143, 2007.

[49] O. Orliac, A. Rouilly, F. Silvestre, and L. Rigal, "Effects of additives on the mechanical properties, hydrophobicity and water uptake of thermo-moulded films produced from sunflower protein isolate," Polymer, vol. 43, no. 20, pp. 5417-5425, 2002.

[50] N. Tudorachi, C. N. Cascaval, M. Rusu, and M. Pruteanu, "Testing of polyvinyl alcohol and starch mixtures as biodegradable polymeric materials," Polymer Testing, vol. 19, no. 7, pp. 785-799, 2000.

[51] F. Parvin, M. A. Rahman, J. M. M. Islam, M. A. Khan, and A. H. M. Saadat, "Preparation and characterization of starch/PVA blend for biodegradable packaging material," Advanced Materials Research, vol. 123-125, pp. 351-354, 2010.

[52] S. Ghoshal, M. A. Khan, F. Gul-E-Noor, and R. A. Khan, "Gamma radiation induced biodegradable shellac films treated by acrylic monomer and ethylene glycol," Journal of Macromolecular Science A, vol. 46, no. 10, pp. 975-982, 2009.

[53] R. K. Wanchoo and P. K. Sharma, "Viscometric study on the compatibility of some water soluble polymer-polymer mixtures," European Polymer Journal, vol. 39, no. 7, pp. 1481-1490, 2003.

[54] S. Tang, P. Zou, H. Xiong, and H. Tang, "Effect of nano- $\mathrm{SiO}_{2}$ on the performance of starch/polyvinyl alcohol blend films," Carbohydrate Polymers, vol. 72, no. 3, pp. 521-526, 2008. 

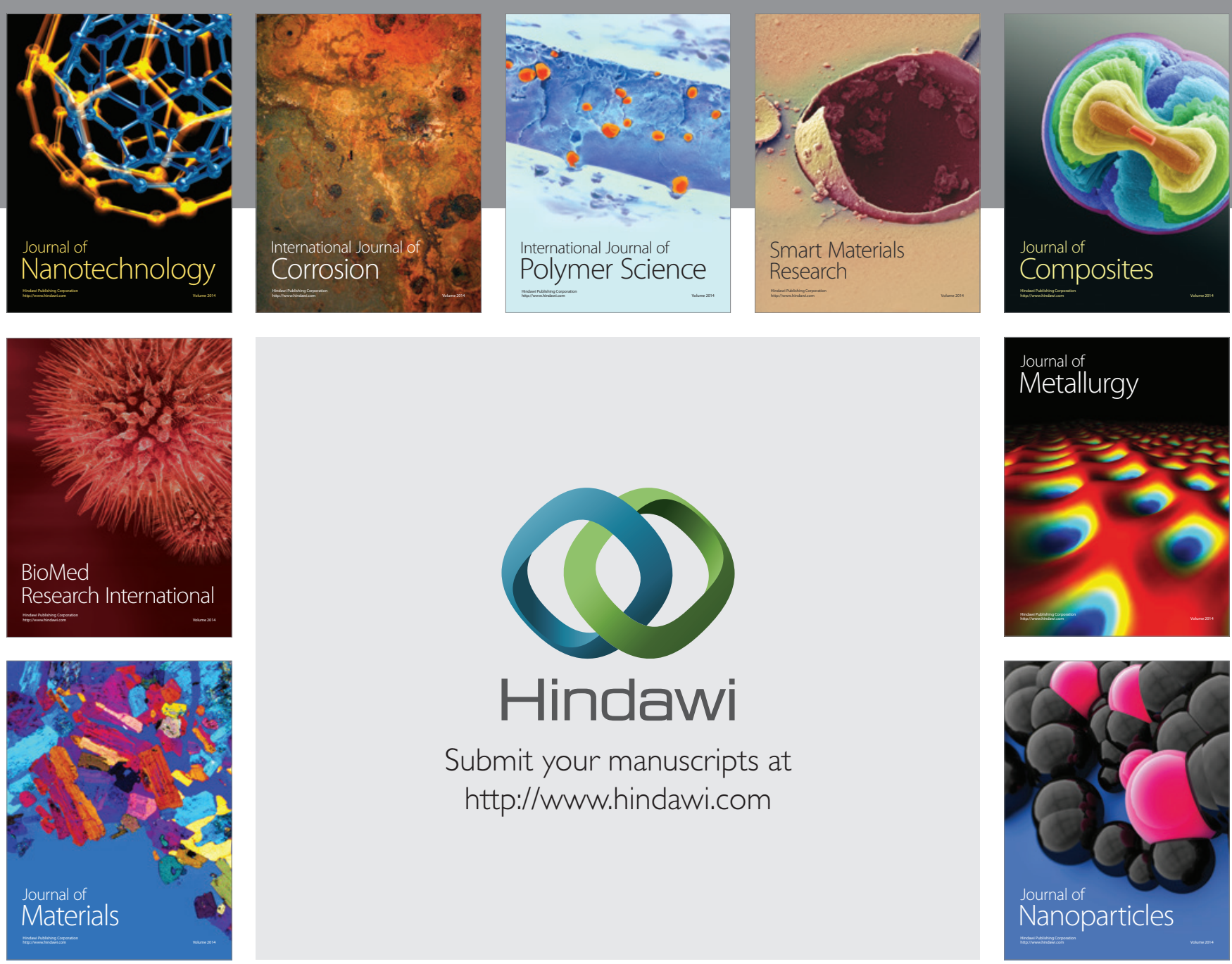

Submit your manuscripts at http://www.hindawi.com
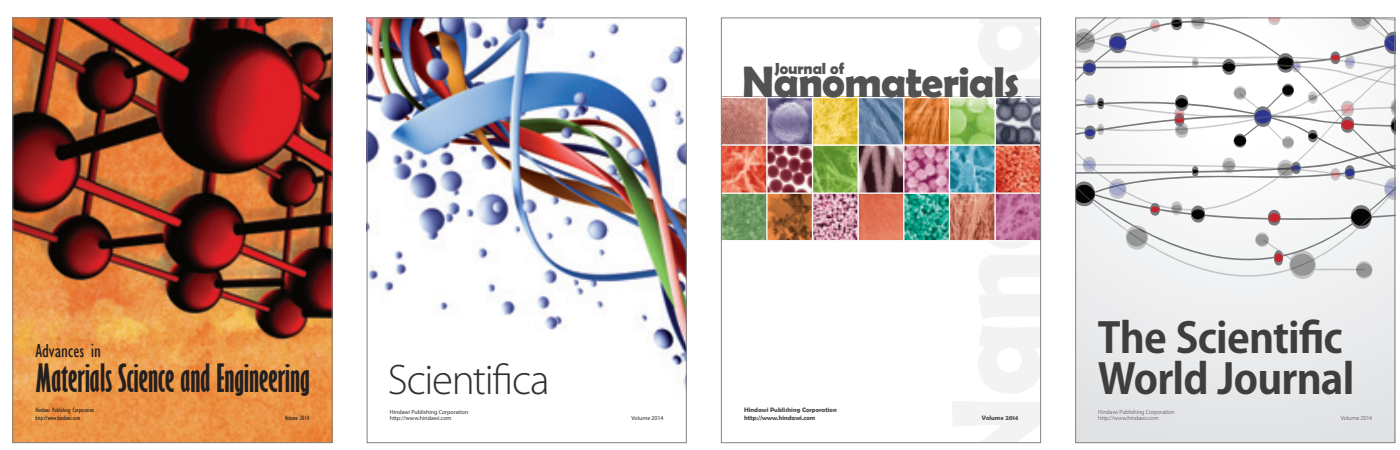

\section{The Scientific World Journal}
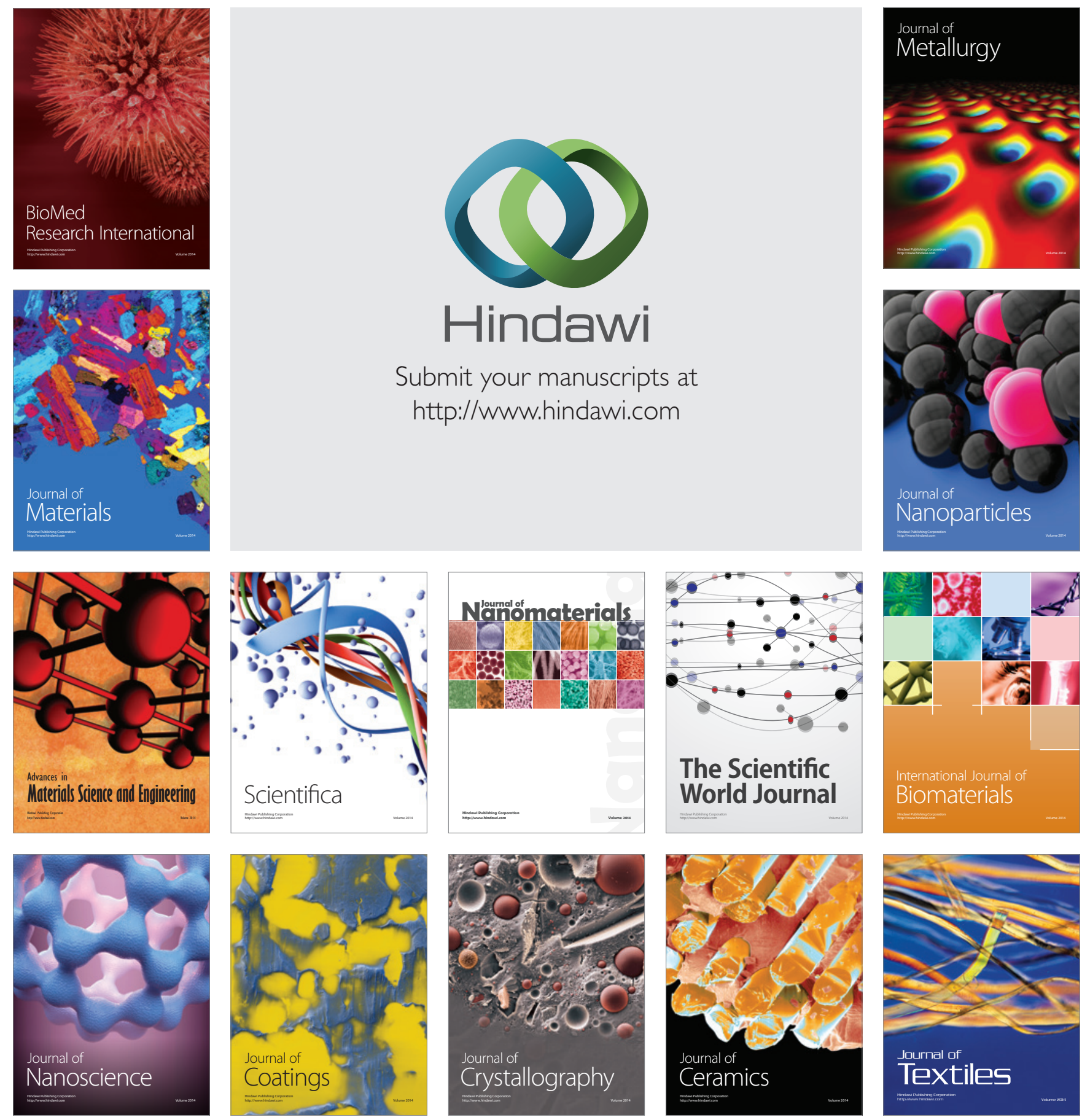